\title{
Equity Market Microstructure: Taking Stock of What We Know
}

The road from theory to a real marketplace is indeed bumpy

Reto Francioni

CEO, Deutsche Börse

Sonali Hazarika

Assistant Professor of Finance

Zicklin School of Business

Baruch College, CUNY

Martin Reck

Managing Director, Deutsche Börse

\author{
Robert A. Schwartz \\ Marvin M. Speiser Professor of Finance \\ Zicklin School of Business \\ Baruch College, CUNY
}

Journal of Portfolio Management, Fall 2008, forthcoming

Draft: November 5, 2007

Please do not quote or distribute without permission of the author 


\title{
Equity Market Microstructure: Taking Stock of What We Know
}

\begin{abstract}
For over three decades, microstructure literature has grown and trading systems around the world have been reengineered into modern electronic platforms. This paper considers these developments, concentrating on microstructure issues that are germane to equity market architecture, and focusing on the design of one trading facility, Deutsche Börse's Xetra. Important insights were gained from the microstructure literature during Xetra's planning period (1994-1997), and Xetra's implementation has marked a huge step forward for Germany's equity markets. Nevertheless, academic research and the design of a real world marketplace remain works in progress.
\end{abstract}




\section{Equity Market Microstructure: Taking Stock of What We Know}

Security market microstructure addresses issues that involve the implementation of portfolio (investment) decisions in a marketplace. Implementation entails the placement and handling of orders in a securities market, and their translation into trades and transaction prices. The process links fundamental information concerning equity valuation (which is of primary concern to portfolio managers) to prices and transaction volumes that are realized in the marketplace. The quality of the link depends on the rules, procedures, and facilities of a securities market, and on the broader regulatory and competitive environment within which the market operates.

Widespread interest on the part of the securities industry, government, and academia is testimony to the importance of market microstructure analysis. The subject addresses issues that concern investors, broker/dealer intermediaries, market regulators, exchanges and other trading venues as well as the broad economy. Interest in microstructure has increased sharply over the past three and a half decades, spurred in particular by three events: the U.S. Securities and Exchange Commission's (SEC) Institutional Investor Report (1971), the passage by the U.S. Congress of the Securities Acts Amendments of 1975, and the sharp stock market drop on October 19, 1987. Further, the advent of computer driven trading in recent years has enabled researchers to capture electronically the full record of all trades and quotes, and this has provided empirical researchers with far richer data (referred to as "high frequency data") for analyzing trading and price setting.

Over the years, microstructure analysis has expanded and exchange structure has strengthened. We consider both of these developments in this paper. First, we set forth the major challenges that the microstructure literature addresses. We next present a broad view of the direction in which microstructure analysis has been and is evolving. Third, we turn to one application - the design of an actual marketplace: Deutsche Börse's electronic trading system, Xetra. The German market was the last of the major European bourses to introduce an electronic trading platform, Xetra, and it is state of the arts, which makes Deutsche Börse a particularly interesting case in point. Then, in the concluding 
section, we consider the bumpy and hazardous road that takes us from theory to the development of a marketplace.

\section{Microstructure’s Challenge}

Microstructure analysis has four broad applications. First (and this is a key focus of the paper), it gives guidance to market structure development. The link with market structure is straightforward: the critical factor that drives microstructure analysis is friction in the marketplace (i.e., the explicit and implicit costs of implementing portfolio decisions), and trading costs depend on the architecture of the marketplace which determines how orders are handled and turned into trades. The flipside of friction is illiquidity. A primary function of a market center is to amass liquidity, and liquidity considerations were continually kept in mind during the development of Deutsche Börse's electronic trading platform.

Microstructure's second application is to facilitate the development of trading strategies and algorithms for asset managers and broker/dealer intermediaries. The importance of this application is evident in the current development of computer driven algorithmic trading. Algorithms can be fine tuned to take account of, e.g., the probability of a limit order executing, time of day effects such as market openings and closings, the search for liquidity in a fragmented environment, and the choice of a trading modality (e.g., a continuous limit order book market, a quote driven dealer market, a periodic call auction, a block trading facility, or hybrid combinations of the above).

The third application of microstructure analysis concerns tests of market efficiency. In the 1970s, at a time when the subject was first emerging, the Efficient Markets Hypothesis (EMH) was widely accepted by financial economists as a cornerstone of modern portfolio theory, and it continues to receive broad academic support today. The hypothesis addresses informational as distinct from operational efficiency (the later refers to the containment of transaction costs by superior market design). According to the EMH, a market is informationally efficient if no participant is able to achieve excess risk adjusted returns by trading on currently available information. Many of the EMH tests have considered one major part of the information set - market information (e.g., recent quotes, trading volume, and transaction prices). If prices 
properly reflect all known information, then (in a frictionless market at least) they must change randomly over time; hence the term "random walk.” Earlier studies, based on daily data, generally supported the random walk hypothesis. However, with the advent of high frequency data, the footprints of complex correlation patterns have been detected. This observation, along with superior knowledge of the impact of trading costs on returns behavior, is casting a new light on market efficiency. Whether inefficiency is thought of in operational or informational terms, the EMH is not as stellar as it once was.

In its fourth application, microstructure analysis sheds light on how new information is incorporated into security prices. In a zero cost, frictionless environment, share values would be continuously and instantaneously updated with the release of new information. In actual markets, however, information must be received and assessed, traders' orders must be placed and processed, and executions must be delivered and accounts cleared and settled. Costs, both explicit (e.g., commissions) and implicit (e.g., market impact), are incurred throughout this chain of events. Highlighted in much of the microstructure literature are the costs that some participants incur when, in an asymmetric information environment, other participants receive information first and trade on it to the disadvantage of the uninformed.

Asymmetric information is not the only reality, however. In light of the size, complexity, and imprecision of much publicly available information, one might expect that investors in possession of the same (large) information set will form different expectations about future risk and return configurations. This situation is referred to as

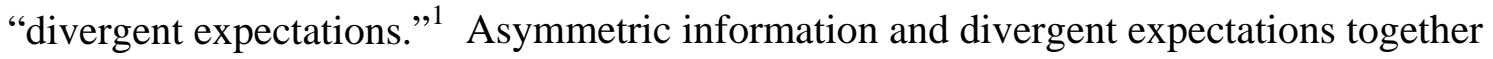
reflect a rich set of forces that impact the dynamic behavior of security prices.

This overview of microstructure's four broad applications underscores that trading frictions are the subject's raison d'être. Participant orders cannot be translated into trades at zero cost (markets are not perfectly liquid), and trades typically are not made at market clearing (i.e., equilibrium) prices. Trading decision rules (algorithms) are needed because the costs of implementing portfolio decisions can sharply lower portfolio performance. In fact, much algorithmic trading is designed to control trading costs, rather than to exploit profitable trading opportunities. Today, trading is recognized as an

\footnotetext{
${ }^{1}$ For a current discussion, see Davis, Pagano and Schwartz [2007].
} 
activity that is both distinct from investing and equivalently professional. Market structure is of concern to the buyside desks precisely because markets are not perfectly liquid, and neither are they perfectly efficient, either informationally or operationally. Consequently, better market structure delivers superior portfolio performance for participants.

What is the economic service, one might ask, that an equities market provides? The fuzzy link that connects information and prices in the non-frictionless environment underscores two major market functions - price discovery and quantity discovery. Price discovery refers to participants collectively searching for equilibrium prices. Quantity discovery refers to the difficulty that participants who would be willing to trade with each other actually have finding each other and trading when markets are fragmented. This difficulty is accentuated because some participants (primarily institutional investors) do not immediately reveal the total size of their orders (doing so would unduly drive up their market impact costs).

Market structure affects both the accuracy of price discovery and the completeness of quantity discovery. The link between market structure and price discovery depends on the environment within which participants are operating. At one end of the spectrum, investors can be equally informed and form homogeneous expectations based on the information. At the other end, they can be differentially informed and form divergent expectations with regard to commonly shared information. When investors who share common information all agree on share values (i.e., have homogeneous expectations), prices can be “discovered” in the upstairs offices of research analysts. When investors are not equally informed, and when they form different expectations based on common information, prices must be discovered in the marketplace. In this second environment, the economic service provided by the exchange is clear - it "produces the price."

Regarding quantity discovery, handling the orders of large institutional customers is a challenge. It is not at all uncommon for an institution to want to buy or to sell 500,000 shares of a company that has an average daily trading volume of 300,000 shares. Executing an order of this size can easily drive prices away from the trader before the job is complete. The adverse price move is a market impact cost. Institutions attempt to 
control their market impact costs by trading patiently and, as much as possible, invisibly. Good market structure can help. To this end, a number of alternative trading systems (ATSs) have been formed in recent years, and dark (i.e., non-transparent) liquidity pools have emerged.

With prices discovered in the marketplace, participants employ trading strategies when they come to the market to implement their portfolio decisions. Participants with differential information that will soon become public determine how best to meter their orders into the market so as to move prices to new levels with minimal speed. Additional questions that any trader might ask include: "If I trade now, at the current moment, how will the price that I will receive compare with the average price that shares are trading at today?” “Is price currently at a sustainable, validated level, or is it likely to move higher or lower in the coming hours, minutes, or even seconds? "Would I do better to be patient and place a limit order, or submit a market order and get the job done right away?" "Should I attempt to trade now in the continuous market, or wait for a closing call?” The orders that a set of participants reveal to the market depend on how questions such as these are answered, and prices that are set and trading volumes that are realized depend on the orders that are revealed.

The categories of trading costs that receive the most attention on the part of exchanges, regulators, and academicians are generally those that are the most straightforward to measure: commissions and bid-ask spreads. Increasingly, precise measures of market impact are also becoming available, and this cost too is being widely taken into account. On the other hand, the opportunity cost of a missed trade, being far more difficult to quantify, is often overlooked. An even greater challenge is quantifying a cost that has received little formal attention: realizing executions at poorly discovered prices. The problem, of course, is that equilibrium values are not observable and appropriate benchmark values are not easily defined.

\section{What Microstructure Analysis Has to Offer: Personal Reflections}

In this section we review the development of microstructure analysis. Our objective is not to provide a comprehensive survey of the literature, but to highlight some of the important themes that can give guidance to market structure development. More 
detailed information can be obtained from Cohen, Maier, Schwartz and Whitcomb [1979] who have provided an early survey of the field; from O’Hara [1995] who discusses important theoretical microstructure models; from Madhavan [2000], Biais, Glosten and Spatt [2005], and Parlour and Seppi [2008] who have provided more recent surveys; and from Hasbrouck (2007) who deals with empirical microstructure research and research methodology. We first focus on the early literature, then turn to more recent developments, and lastly present our thoughts concerning an important direction in which future microstructure research ought to head.

\section{The Early Focus}

The first contributions to the new field in financial economics that came to be called “microstructure” were made by a couple of people who participated in the SEC's Institutional Investor Report (1971). A handful of others independently started to focus on microstructure topics in the early 1970s. Eventually a few of the early researchers came to recognize the commonality of their interests and, applying the title of Garman's [1976] well known paper, "Market Microstructure,” they gave the field its name.

Much of the early literature focused on dealers and exchange specialists. These market makers were viewed as the suppliers of immediacy to investors, and the spread was considered the price they charge for providing this service in an environment where order arrival is non-synchronous. Of key importance was the relationship between spreads and the costs of market making.

The earlier market maker studies were in large part motivated by a desire to determine whether or not these intermediaries were realizing monopoly profits and, if so, whether or not their profits were attributable to market making being a natural monopoly. Spreads that are greater than the costs of market making would be taken as an indication of monopoly power on the part of the dealers, and spreads that were negatively related to trading volumes would indicate economies of scale in market making, which could imply a natural monopoly (Stigler [1964]). Spreads were indeed found to decrease with transactions volume, but reasons other than market making being a natural monopoly were advanced (Smidt [1971], Tinic [1972]). 
The general picture which emerged was that the trading costs incurred by investors could be lowered by strengthening competition between market maker intermediaries. In particular, competition in the NYSE market was deemed inadequate, as specialists and the Exchange itself were viewed as having monopoly positions: each stock was assigned to just one specialist; the NYSE's order consolidation rule (Rule 390) precluded in-house executions by requiring that exchange members send their orders for NYSE listed securities to an exchange; and commissions were both fixed and unjustifiably high (Tinic and West [1980]). ${ }^{2}$

Not surprisingly, the focus on the market maker firms led several researchers to model market maker pricing decisions (i.e., the setting of their bid and ask quotes). These included Bagehot [1971], Stoll [1978], Amihud and Mendelson [1980], Ho and Stoll [1980, 1981, 1983], and Mildenstein and Schleef [1983]. With one exception (Bagehot [1971]), the early formulations focused on inventory considerations. A market maker firm holding an undesirably long position would lower the quotes (i.e., lower the offer so as to sell more shares, and reduce the bid so as to discourage others from selling shares to it). Reciprocally, a market maker who was short would raise the quotes. A variety of mathematical tools were used to solve for optimal market maker quotes. These models also gave further insight into the cost components of the market maker's spread.

While insightful, the early inventory-based pricing models suffered from some shortcomings. First, the early formulations for the most part assumed monopoly market makers, even though some of these models were applied to markets such as the New York Stock Exchange were exchange specialists in fact competed with other floor brokers and customer limit orders (Demsetz [1968]). The application of theory further suffered from the reality that the price of immediacy for an investor is not the spread of an individual market maker, or even the average market maker spread, but the inside spread (i.e., the lowest ask across all market makers minus the highest bid). ${ }^{3}$ It is important to note that dealer spreads could individually remain relatively invariant with respect to transaction volume while the inside spread fell appreciably.

\footnotetext{
${ }^{2}$ Another major issue addressed by the microstructure literature at that time was the impact of information on trading volume and price (Copeland [1976], Beja and Hakansson [1977] and Beja and Goldman [1980]).

${ }^{3}$ For further discussion, see Cohen, Maier, Schwartz and Whitcomb [1979].
} 
A further shortcoming of most of these earlier models is that they did not take account of a major cost incurred by a market maker: the loss incurred from trading with a better informed investor. Recognition of this reality led to a development that did much to establish microstructure as an important new field in financial economics - the introduction of market maker models that were based, not on inventory management, but on controlling the cost incurred when some investors are in possession of information that the market maker and other investors have not yet received. Bagehot [1971] was the first to embark on this line of thought. He was later followed by, among others, Gloston and Milgrom [1985] and Kyle [1985].

With information asymmetries, the market maker always looses when trading with a better informed participant. For microstructure theorists at the time, this meant that, for the dealer market to not fail, some investors must trade for reasons that are not related to information. ${ }^{4}$ Liquidity considerations (i.e., an investor's personal cash flow needs) was one such motive for public buying and selling. A third participant type was also introduced along with the liquidity traders - noise traders (participants who trade on price moves as if they contained information when in fact they do not). This trio of informed traders, liquidity traders, and noise traders was used to show a how markets could function and, in so doing, enable new information to be incorporated into security prices (Grossman and Stiglitz [1980], Milgrom and Stokey [1982], Kyle [1985], Glosten and Milgrom [1985], Copeland and Galai [1983], and Easley and O’Hara [1987, 1991, 1992]).

At this stage of its early development, the microstructure pricing models were predominantly market maker models. One exception should be noted, however: a National Book System proposed by Mendelson, Peake and Williams [1979] contained a comprehensive description of an order driven automated trading system that provided guidance for designing the first exchange-based electronic trading systems. For a more recent discussion of automated trading systems, see Domowitz and Steil [1999]. Most equity markets around the globe are now order driven, limit order book markets that might include market makers in a hybrid structure (as does the NYSE), but are not

\footnotetext{
${ }^{4}$ A market supported by informational trading only can indeed function if agents trade with each other because their expectations are divergent. When the information that triggers trading is common knowledge, the condition may be thought of as one where agents are agreeing to disagree.
} 
basically quote driven (i.e., dealer) markets (as was the old Nasdaq and London Stock Exchange). The limit order book markets are driven by the orders placed by the investors themselves, not by market maker intermediaries.

The Current Focus

Over the years, microstructure analysis has grown extensively on both theoretical and empirical fronts. Concomitantly, the securities markets themselves have evolved, becoming ever more technologically developed, more global in outreach, but also more fragmented between different trading facilities. One important new direction microstructure research has taken is to model the order driven market, an environment where natural buyers and sellers provide immediacy to each other because some, who are patient, are willing to post limit orders while others, who demand immediacy, choose to submit market orders that execute against the posted limit orders. Understanding the costs of, and motives for, placing limit orders as distinct from market orders was called for.

With limit orders, the very existence of the bid-ask spread has to be explained. That is, with a sufficiently large number of participants placing limit orders, one might expect that orders would be posted at virtually every available price point in the neighborhood of equilibrium, and that the spread would disappear. Cohen, Maier, Schwartz and Whitcomb (CMSW) made this point in their review paper (CMSW [1979]), and they analyzed the existence of the spread in CMSW [1981]. ${ }^{5}$ They further write, "With regard to modeling the market spread, we suggest that a straightforward aggregation from individual spreads is not possible in a system where there is no clear distinction between demanders and suppliers of immediacy, and where traders meet in a dynamic, interactive environment that incorporates the impact of investor order placement strategies.” Strategic order placement clearly required further analysis.

The analysis, however, was not a simple task. Some of the first papers in this area assumed, as is true for a dealer market, that limit order and market order participants are two separate, exogenously fixed groups that are separated by a firewall (Glosten [1994]). This assumption, while simplifying mathematical modeling, unfortunately distills out

\footnotetext{
${ }^{5}$ Cohen Maier, Schwartz and Whitcomb [1981] describe the trade-off between execution probability and price improvement in the optimal choice between limit and market orders.
} 
much of the richness of an order driven market. More recent models have eliminated the firewall (Handa and Schwartz [1996a], Foucault [1999], Parlour [1998], Handa, Schwartz and Tiwari [2003], Faucault, Kaden and Kandel [2005], Goettler, Parlour and Rajan [2005]). With the choice between limit order and market order endogenous, for any market to function, participants must divide naturally into four groups which reflect two dichotomies (one between buyers and sellers and the other between limit order and market order placers), not the standard two (buyers and sellers).

With order type selection endogenous in the order driven market, the balance between immediacy suppliers and immediacy sellers becomes a second equilibrium that must be understood. One needs to recognize the conditions under which some participants will choose to be liquidity demanders (place market orders) while others choose to be liquidity suppliers (place limit orders). If a reasonable balance is not achieved between these two groups, the order driven market will fail (as indeed it does for thinner, small cap stocks). Increasingly, these issues have been handled, and some sophisticated limit order models have been developed. ${ }^{6}$

The microstructure analysis of trading systems has expanded to include periodic call auctions. $^{7}$ The economics of a call auction are quite different from those of continuous trading and, consequently, so too are the order placement strategies that participants should employ when they approach a call market. Call auctions do not, by their very nature, supply immediacy. Rather, orders that are entered during a call's bookbuilding phase are held for a periodic crossing at a single clearing price at the (generally predetermined) time of the market call. Buy and sell orders submitted to a call do not execute when they arrive even if they match or cross in price (matching and crossing orders execute immediately in a continuous trading environment). This being the case, limit and market orders have a different meaning in a call: limit orders do not supply immediacy to market orders, and market orders are simply extremely aggressively priced limit orders (i.e., a market order to sell in a call effectively has a limit price of zero, and a market order to buy effectively has a limit price of infinity).

\footnotetext{
${ }^{6}$ See Bach and Baruch [2007] for a recent discussion and further references.

${ }^{7}$ See Economides and Schwartz [1995] for a description of alternative call market structures.
} 
Today, virtually all modern, electronic exchanges open and close their continuous markets with call auctions. Consequently, participants face further decisions when operating in a call plus continuous, hybrid market: how to submit an order to a call auction which is followed by continuous trading (e.g., an opening call), and how to submit an order to a continuous trading environment that is followed by a call auction (e.g., a closing call). Taking these tactical decisions into account is part of the complexity of microstructure analysis.

Technological developments have simultaneously enabled new trading venues to emerge (which can fragment markets) while providing connectivity between them (which can consolidate markets). Concurrently, regulatory initiatives have been motivated by the desire to increase inter-market competition. Questions can be raised, however, concerning fragmentation of the order flow. The conventional wisdom has been that the consolidation of order flow improves liquidity, and exposing each order to all other displayed orders gives investors the best prices for their trades. Consolidating trading in a single market provides incentives to liquidity suppliers to compete aggressively for market orders by revealing their trading interest, and by being the first to establish a more favorable price (if time is used as a secondary priority rule).

On the other hand, arguments in favor of trading on multiple markets include the benefits of inter-market competition, and the fact that traders with disparate motives for trading may want different marketplaces to trade in. And so, different markets develop to serve diverse investor needs (such as achieving a faster execution vs. obtaining a better price). One growing need among large institutional investors, the ability to trade large orders with minimal market impact, has led to the advent of dark pool, block trading facilities such as Liquidnet, Pipeline, and ITG's Posit that aid in quantity discovery. This development in the industry has spawned a related line of research on off-exchange and upstairs trading (Grossman [1992], Seppi [1990], Madhavan [1995], Keim and Madhavan [1996] and Madhavan and Cheng [1996]).

A spectrum of market quality issues have been of long and continuing importance to microstructure researchers. These include market transparency (both pre- and posttrade), the accentuation of intra-day price volatility, and correlation patterns which have been observed in high frequency data. Other important issues include price clustering and 
tick sizes (Harris [1991, 1994]). Applications such as transaction cost analysis (TCA) and algorithmic trading have received increasing attention (Domowitz [2001]). The relative performance of floor based vs. electronic trading is another important issue [Domowitz and Steil, 1999].

Numerous empirical studies have focused on two of the world's premier markets, the New York Stock Exchange and Nasdaq (Hasbrouck [1991, 1995] Hasbrouck and Sofianos [1993], Christie and Schultz [1994], Christie, Harris and Schultz [1994]. Many other studies have considered European markets, Asian markets, and other markets around the world [e.g., Biais, Hillion and Spatt [1995], Sandas [2001] and Ozenhas, Schwartz and Wood [2002]. ${ }^{8}$ Across all of these markets, structural and performance differences have been noted, but also major similarities have been observed. It is apparent that, despite the influence of historic and cultural considerations, trader behavior and market performance around the globe depend largely on microstructure considerations. Alternatively stated, trading rooms and markets around the world bear striking resemblances to each another.

Another recent line of research has considered how search costs affect bid-ask spreads in financial markets. To this end, Duffie, Perderson and Garleanu [2005] present a dynamic model of market makers under the assumption of no inventory risk and information that is symmetrically distributed. They show that sophisticated investors who have better search and bargaining abilities face tighter bid-ask spreads. This is in contrast to traditional information-based models which imply that spreads are wider for more sophisticated (i.e. better informed) investors.

As we have noted, amassing liquidity is a primary function of a marketplace and market structure features are generally designed with liquidity implications in mind. Portfolio managers also take liquidity into account, along with the two other standard variables, risk and return. Difficulties in defining, measuring, and modeling liquidity are formidable, however, and the literature that deals with it directly is relatively sparse

\footnotetext{
${ }^{8}$ Also see Bessler [2006] for discussion and further references.
} 
(Bernstein [1987]). Nevertheless, liquidity considerations have permeated the microstructure literature, both explicitly and implicitly. ${ }^{9}$

Looking back over the development of microstructure analysis, two observations stand out. First, microstructure studies have in multiple ways given direction to market structure development. Second, to a remarkable extent, the various theoretical microstructure models that are center stage today, and many empirical analyses that are based upon them, share a common structural framework - the asymmetric information paradigm. This consistency is desirable in that it implies that the field has grown by accretion rather than by replacement. Consequently, new conclusions are more apt to refine than to contradict old conclusions.

Consistency, however, is not desirable if the common structural framework becomes overly rigid and restrictive, and if it yields incomplete and/or misleading answers to questions involving trader behavior, market structure, and regulatory policy. At times, a literature starts to advance along new fronts. We consider this possibility next for the microstructure literature.

\section{Future Directions}

As we have noted, the current focus in the literature is on asymmetric information based models, which are characterized as follows. Trading is driven by informational change, liquidity needs, and noise trading. The information motive for trading is the first mover of the three (liquidity and noise trading are required so that the market will not fail). Further, order arrival in the continuous environment is generally taken to be asynchronous. For a continuous trading regime to function with asynchronous order arrival, the presence of a limit order book and/or a market maker intermediary is required. Information trading is of keen interest because it represents the process by which new information is reflected in share values. In the standard asymmetric information models, it is assumed that all participants in possession of the same information form equivalent expectations concerning future risk and return configurations. When information changes, however, participants may not all receive the news at the same

\footnotetext{
${ }^{9}$ For further discussion and references regarding liquidity see Amihud and Mendelson [1986], Chordia, Roll and Subrahmanyam [2000], Hasbrouck and Seppi [2001], Amihud [2002] and Pastor and Stambaugh [2003]
} 
time; some receive it before others, a reality that, at any point in time, divides traders into two groups - the informed and the uninformed. Informed participants will never trade with each other; consequently, liquidity and noise traders must be present for a market to function. As noted, asymmetry of information, for the most part, lies at the heart of the standard microstructure models of today.

The standard homogeneous expectations assumption has been tempered of late. It is being recognized that some participants produce "private information” (namely, that they further process information so as to gain insights that are not immediately available to others). Whether participant expectations differ because of the actual production of private information, or simply because different people interpret the same information or news announcement differently, the expectations of a group of investors can be divergent.

Also at the heart of the asymmetric information models is the presumption that a stock has a fundamental value that bears a unique relationship, not to trader activity in the marketplace, but to the fundamental information that informed traders possess. The process of information being fully reflected in prices under asymmetric information is the act of informed and uninformed agents trading with each other until any discrepancy between a market price and a fundamental value is eliminated. In the earlier dealer models, the market maker was assumed to know a stock's fundamental value. In later models, informed traders but not the market maker knows the fundamental values [Kyle [1985]. Especially in the later models, price discovery is not instantaneous; rather it is a protracted process that depends on the individual strategies employed by the informed and uninformed agents.

In recent years, an alternative paradigm has been emerging: a divergent expectations environment [Miller, 1977]. While institutionally realistic, this paradigm has met with considerable academic resistance. For one thing, homogeneous expectations environments are far easier to model mathematically and homogeneity has, in many applications, proven to be a useful modeling assumption. The assumption has also been retained for another reason. As an attribute of individual rationality, it is presumed that intelligent agents facing the same information and applying the same (correct) analytic techniques will reach the same conclusions and, therefore, will have homogeneous expectations. 
Fundamental information, however, is enormous in scope, complex, and imprecise. In the presence of fuzzy information, expectations can be divergent. Allowing for divergent expectations opens another path for microstructure analysis, and it introduces new questions concerning agent behavior, market structure, and regulatory policy. Moreover, a second element can enter the analysis in a divergent expectations environment: along with forming their own opinions, agents may also respond to the opinions of others; i.e., exhibit adaptive valuation behavior (Paroush, Schwartz and Wolf [2007] and Davis, Pagano and Schwartz [2007]). ${ }^{10}$ Just how agents communicate with each other and respond to each others' opinions is a subject for ongoing research. The topic also opens another interface with behavioral finance.

Price discovery acquires a different meaning in a divergent expectations environment, and this has important implications for market structure. When asymmetric information characterizes a community of investors, the strategic behavior of informed agents can affect the path that price takes when news moves a share value from one equilibrium to another, but the new equilibrium is path independent. With divergent expectations, the new equilibrium is path dependent - it depends on how the opinions of a diverse set of agents are integrated (Paroush, Schwartz and Wolf [2007]). Alternatively stated, with divergent expectations, price discovery is a coordination process and, as such, is directly effected by market structure.

In the standard asymmetric information environment, the key dichotomy is between informed and uninformed participants. But a second dichotomy also exists one that separates large institutional customers from small retail customers. One might expect that the informed investor set would largely comprise the institutional customers. After all, the institutions are professional, they can afford to continuously monitor information and respond to news, and their very size (all else constant) reduces their per share cost of doing so. With divergent expectations, however, there is no presumption that institutional customers can, because of their size, consistently evaluate shares more accurately. On the contrary, institutions commonly disagree with each other and, as a consequence, commonly trade with each other.

\footnotetext{
${ }^{10}$ Adaptive valuation behavior refers to individual agents becoming more bullish (bearish) when learning of the relatively bullish (bearish) attitudes of others.
} 
In the divergent expectations environment, institutional investors do not necessarily have an advantage over retail customers as fundamental analysts. In fact, their size makes trading more difficult and they incur higher transaction costs. So what accounts for their popularity? The value added by the mutual funds, pension funds, etc. comes largely from their ability to facilitate diversification. Further, they can bring a systematic, professional, and disciplined approach to portfolio management (Davis, Pagano and Schwartz [2007]).

\section{From Theory to Application}

Microstructure analysis is inherently involved with analyzing the detailed functioning of a marketplace. The literature has a strong theoretical component and, to a large extent, is structured to yield insights into the effect of market design on market performance. Hopefully, theory can provide a broad roadmap for real world market architects to follow. But our roadmap today is incomplete, and it was even more limited in the 1994-1997 years when Xetra was being designed. And, there is always the danger that the cartographer whose map is being used has some misconceptions (e.g., believes in the existence of the Northwest Passage).

Having considered the development of microstructure theory, we now turn to the actual designing of a marketplace. Our focus is on Deutsche Börse: it is the dominant stock exchange in Germany, the last of the major European Borses to go electronic, and has technology that is state of the art. Important insights were gained from the microstructure literature during Xetra's planning period and the system's implementation has marked a huge step forward for Germany’s equity markets.

We start by providing a brief overview of the German market structure that existed before it was reengineered into a modern electronic marketplace, and then identify ways in which the microstructure literature has and has not been able to provide useful guidance for undertaking this highly complex task.

\section{The German Equities Market in the Mid-1990s}

As recently as the mid-1990s, the German market had major structural defects that would undermine its competitiveness in the European arena. In recognition of this, 
Deutsche Börse, the newly founded exchange operator of the Frankfurter Wertpapierbörse (FWB), became the leading force for change. ${ }^{11}$

In the mid-1990s, Frankfurt's trading floor was the major marketplace for German stocks, but the German market was badly fragmented. Kursmaklers, the equivalent of specialists, concentrated much of the liquidity in their order books. A primitive (by today's standards) electronic trading system, IBIS (which was owned by FWB), operated in parallel with the floor trading. IBIS's central component was an open limit order book that had hit and take functionality, but did not match orders automatically. The electronic system captured about $40 \%$ of the trading volume in the 30 large-cap DAX stocks, but no link existed between IBIS and the floor. Seven other floor-based regional exchanges were also operating in Germany with technical infrastructures that were similar to those in Frankfurt. In total, the regionals at that time were attracting roughly10\% of German exchange-based trading volume. Moreover, off-board trading has been (and still is) prevalent in Germany (Davis, Pagano and Schwartz [2006]).

Transparency for floor trading (pre-trade transparency in particular) was low. Quotes were not distributed publicly (they were available on the floor only). Price priority between different trading venues was not enforced and orders executed in one market commonly traded through orders waiting to be executed in another market. Market manipulation and other abuses of power and position were believed to be rife on the old Frankfurt floor. Given the appreciable market fragmentation, poor transparency, imperfect inter-market linkages, and dubious floor behavior, transaction costs were high. Changes, both structural and regulatory, were called for. The result was the development of Xetra, an electronic order-driven trading system that comprises two principal modalities - a continuous order book platform and periodic single-price call auctions. ${ }^{12}$

\section{Designing a New Trading System}

Xetra’s development started in 1994, and the system was launched in 1997. Strong external forces also motivated this reengineering of Deutsche Börse's market structure: regulatory reform, soaring trading volumes, pan-European harmonization of the

\footnotetext{
${ }^{11}$ FWB also owned the futures and options exchange Deutsche Termine Börse. After the 1997 merger with SOFFEX, DTB became Eurex.

${ }^{12}$ For further discussion and descriptions, see Francioni, Hazarika, Reck and Schwartz [2008].
} 
exchange industry, vibrant cross-border competition for order flow, and the rising concerns of market participants about the future performance of Germany's financial markets.

Through Xetra's design stage, microstructure theory, even as it existed at the time, was an indispensable guide. This new field in financial economics, with its origin in issues concerning the competitive and architectural structure of an equity market, should have been able to give guidance to the development of an actual marketplace such as Xetra. To an extent, it has fulfilled its promise. The literature gave Deutsche Börse a broad roadmap, and it has highlighted underlying relationships and other important considerations that a market architect should be aware of.

Building the Xetra model involved specifying principles that the new market should implement, and the system's functionality also had to be defined. Most importantly, the new market system was to provide equal and decentralized access to all of its participants. Further, the system's functionality and the market information delivered to users (both pre- and post-trade) were to be the same for all traders. A trader's location should not matter. With this in mind, Deutshe Börse's fundamental architectural decision was to structure a hybrid market that included two major modalities - a continuous electronic order driven platform, and periodic call auctions that were used primarily for market openings and closings. ${ }^{13}$

An absolutely critical attribute of an order driven trading system is its ability, visà-vis its competitors, to win the battle for liquidity. Regarding this matter, the earlier microstructure literature has given some guidance, but liquidity is a complex attribute to deal with. As it is not easy to define and measure, liquidity has been very difficult to model and assess. However, as noted above, the measurement and analysis of liquidity are currently attracting considerably more attention in the microstructure literature.

Price discovery and transparency are two other issues for which the microstructure literature has provided valuable guidance. The architects at Deutsche Börse recognized that price discovery is a primary function of a market center, and their major reason for introducing the call auctions was to sharpen its accuracy, particularly at

\footnotetext{
${ }^{13}$ Interestingly, the microstructure literature on call auctions was relatively sparse at that time. For an early discussion, see Handa and Schwartz [1996b].
} 
market openings and closings. Understanding that transparency is important while recognizing that it should not be excessive, the decision was made to disclose only the indicative clearing price (not the full book of orders) in the pre-call, bookbuilding period.

Microstructure literature has given insights into the operations of the public limit order book for continuous trading. At the time, recognition was also emerging of periodic call auctions, a modality that was clearly differentiated from, but could effectively be used with, the continuous market. With regard to continuous trading, microstructure analyses of the use of limit and market orders and of the interaction between these two order types proved to be most valuable. However, a deeper understanding of the economics of an order driven market now exists than was the case in the 1994-1997 period when Xetra was being designed.

Another important contribution of microstructure theory has been the classification of traders according to their needs for immediacy and their propensities to be either givers or takers of liquidity. The differentiation between informed and uniformed traders also proved to be valuable, particularly with respect to the market maker role that has been incorporated into Xetra. Specifically, market makers, referred to as “designated sponsors,” were included to bolster liquidity provision for smaller cap stocks. To do this, a balance had to be achieved between the obligations imposed on the designated sponsors and the privileges granted to them. To accomplish this, information had to be assessed concerning the role of dealers in general (e.g., NASDAQ market makers) and specialists in particular (e.g., NYSE specialists). That balance defined the designated sponsors' role in Xetra, and secured their willingness to accept it. Market microstructure insights also yielded the understanding needed to transform the specialist role into the newly designed designated sponsor role.

But designing an automated trading systems is indeed a complex task, and the gap between theory and implementation is both large and intricate. Trading decisions can be made in a large variety of ways that run the gamut from humans interacting directly with humans without computers, to humans trading via electronic order handling and execution systems, to computers making trading decisions that are sent electronically to a computerized market (e.g., computer driven algorithmic trading). Since the mid-1990s, 
market structure development has involved mainly the design of an electronic trading facility.

Deutsche Börse took account of the fact that automation impacts both the way in which trading decisions are made, and the process by which prices are determined and trades executed in a market center. An electronic market requires the specification of an array of critical features (e.g., the trading modalities employed, rules of price and quantity determination, and basic features such as order types and trading parameters). With an electronic market, the software that implements a desired market structure must be specified on a level of detail which far exceeds what is required for human intermediated trading.

For instance, a human agent (specialist) currently handles price determination at NYSE openings. This function is performed with reference to various rules, but the specialist is also free to exercise reasonable judgment. Further, human-to-human interactions can evolve naturally as problems, opportunities, and new competitive pressures arise. In contrast, with a fully electronic opening, every possible condition that can occur must be recognized and a rule for dealing with it specified, and electronic interaction can be changed only by rewriting the code that specifies with step-by-step precision just how orders are handled and turned into trades and transaction prices.

How does one achieve the precise specifications that a computerized trading system must have? In 1994, the market architects at Deutsche Börse could study the operations of other electronic platforms (e.g., CATS in Toronto and CAC in Paris). Doing so was helpful but of limited value given that Deutsche Börse was looking to develop a distinctive system.

When moving into new territory, market structure development is a venture. How does one know in advance whether or not it will work? How can one determine whether or not the new system will be viable from a business perspective? Nevertheless, design decisions have to be made, technical requirements must be specified, and the system must be built. The decisions involved represent huge financial bets on whether or not a new market structure will attract sufficient liquidity. Prototyping a new market in the design phase helps the assessment process, but doing so was considerably more difficult in 1994 than it is today with the advent of superior information technology and testing 
capabilities. In 1994, the architects were forced to rely more on their own educated judgment and any insights they might gain from microstructure research.

Those who are involved in the design of an actual market realize that the devil is in the details. Consider, for instance, the specification of a call auction. A call has excellent theoretical properties, but how should an actual auction be designed? It is straightforward to say that the market clearing price in a call auction should be the value that maximizes the number of shares that trade. But what should the specific rule be for selecting the clearing price if two prices both result in the same maximum trade size? Additionally, how transparent should the book be in the pre-call, order entry period? Are further design features needed to counter the possibility of gaming? And so on.

Other considerations that for the most part are outside the scope of the microstructure literature also came into play during the design of Xetra. Information technology issues such as scalability, open architecture, and system reliability are of critical importance. So too are procedures for post-trade clearing and settlement. One of the final steps in the structural change of the German market was the introduction in 2003 of a central counterparty (with a CCP, counterparty risk management was centralized and trading became fully anonymous, both pre- and post-trade). Electronic trading is also a prerequisite for highly efficient straight-through processing (STP involves all stages of a trade's life cycle). Information technology has further facilitated the timely capture of market data (all trades, quotes, market index values, etc.) and has expedited its delivery to users. With regard to these diverse applications, Deutsche Börse has achieved a closer integration between trading on Xetra and the broader market infrastructure.

\section{The Roadmap and the Road}

A market architect must have a roadmap that, broadly speaking, says where one ought to head and roughly how to get there. To this end, the microstructure literature has added clarity, articulation, and intellectual support. Briefly stated, the objective is to reduce trading frictions (costs), sharpen price discovery, and facilitate quantity discovery. The means of achieving this broad objective involve the amassing of liquidity. This is done through the appropriate use of limit order books for both continuous and call auction trading and, where appropriate, the inclusion of broker/dealer intermediaries. 
Further insights are gained from microstructure's in-depth analyses of trading motives (new information, liquidity needs, and technical trading signals). The literature has also provided guidance with regard to issues such as transparency and the consolidation (fragmentation) of order flow.

But theory, even if it does provide a good roadmap, can take one only so far. The closer one gets to the design of an actual system, the more apparent the complexities of trading and trading systems become. The road actually traveled is indeed bumpy and hazardous. System designers know that "the devil is in the details." They have to grapple with issues ranging from scalability, reliability, and other IT requirements, to business considerations concerning the ultimate profitability of a trading venue. The market architects at Deutsche Börse recognized these issues and their new system, Xetra, has marked a huge step forward for the German equity market.

Today, important problems persist with regard to market design in Germany (and in all other markets around the world). What is the best way to deal with large, institutional orders? How is liquidity creation best handled for mid-cap and small-cap stock? These are two fundamental questions concerning market architecture that have yet to be adequately answered. At the same time, important microstructure topics continue to emerge at the academic research desks. Are there limits beyond which microstructure theory cannot provide guidance? Are there limits to the level of efficiency that a real world market can ever achieve? Undoubtedly, both answers are “yes” but, without question, neither of these limits has of yet been reached. Quite clearly, microstructure research and the design of an actual marketplace remain works in progress. 


\section{REFERENCES}

Amihud, Yakov. "Illiquidity and stock returns: Cross-section and time-series effects." Journal of Financial Markets, 5, 2002, pp. 31-56.

Amihud, Yakov and Haim Mendelson. ”Asset pricing and the bid-ask spread.” Journal of Financial Economics, 17, 1986, pp. 223-249.

Back, Kerry and Shmuel Baruch. "Working Orders in Limit-Order Markets and Floor Exchanges.” Journal of Finance, 2007, forthcoming.

Bagehot, Walter (pseudonym). "The Only Game in Town." Financial Analysts Journal, (Mar/April 1971), pp. 12-14, 22.

Amihud, Yakov, and Haim Mendelson. ”Dealership market: Market-Making with Inventory.” Journal of Financial Economics, 8, 1980, pp. 31-53.

Beja, Avraham and Nils H. Hakansson. "Dynamic Market Processes and the Rewards to Up-to-Date Information." Journal of Finance, 32, 1977, pp. 291-304.

Beja, Avraham and M. Barry Goldman, “On The Dynamic Behavior of Prices in Disequilibrium”, Journal of Finance, 35, 1980, pp. 235-248.

Bernstein, Peter, “Liquidity, Stock Markets and Market Makers,” Financial Management, Summer 1987, pp. 54-62.

Wolfgang Bessler, editor, Bösen, Banken und Kapitalmärkte, Duncker \& Humblot, 2006

Biais, Bruno., Pierre Hillion, and Chester Spatt. "An empirical analysis of the limit order book and the order flow in the Paris Bourse.” Journal of Finance, 50, 1995, pp. 16551689.

Biais, Bruno, Bruno, Larry Glosten, and Chester Spatt. "Market microstructure: A survey of microfoundations, empirical results, and policy implications.” Journal of Financial Markets, 2005, 8, pp. 217-264.

Chordia, Tarun, Richard Roll and Avanidhar Subrahmanyam. "Commonality in Liquidity.” Journal of Financial Economics, 56, 2000, pp. 3-28.

Christie, William, Jeffrey Harris, and Paul Schultz. Why Did NASDAQ Market Makers Stop Avoiding Odd-Eighth Quotes? Journal of Finance, 49, 1994, pp. 1841-1860.

Christie, William, and Paul Schultz. Why do NASDAQ Market Makers Avoid OddEighth Quotes? Journal of Finance, 49, 1994, pp. 1813-1840.

Cohen, Kalman, Steven Maier, Robert Schwartz, and David Whitcomb. "Market Makers and the Market Spread: A Review of Recent Literature." The Journal of Financial and 
Quantitative Analysis, 1979, 14, pp. 813- 835.

Cohen, Kalman, Steven Maier, Robert Schwartz, and David Whitcomb. "Transaction Costs, Order Placement Strategy, and Existence of the Bid-Ask Spread." The Journal of Political Economy, April 1981, pp. 287 - 305.

Copeland, Thomas. "A Model of Asset Trading under the Assumption of Sequential Information Arrival.” Journal of Finance, 31, 1976, pp. 1149-1168.

Copeland, Thomas, and Dan Galai. "Information effects on the bid-ask spread.” Journal of Finance, 38, 1983, pp. 1457-1469.

Davis, Paul, Michael Pagano, and Robert Schwartz, "Life After the Big Board Goes Electronic," Financial Analysts Journal, Volume 62, Number 5, September/October 2006, pp. 14-20.

Davis, Paul, Michael Pagano, and Robert Schwartz. "Divergent Expectation.” Journal of Portfolio Management, Fall 2007, forthcoming.

Demsetz, Harold. “The Cost of Transacting.” The Quarterly Journal of Economics, 82, 1, 1968, pp. 33-53.

Domowitz, Ian and Benn Steil, "Automation, Trading Costs, and the Structure of the Securities Trading Industry,” Brookings-Wharton Papers on Financial Services, 1999, 3392.

Domowitz, Ian, Jack Glen and Ananth Madhavan, "Liquidity, Volatility, and Equity Trading Costs Across Countries and Over Time,” International Finance 4, 221-256, 2001.

Economides, Nicholas, and Robert Schwartz. "Electronic Call Market Trading." Journal of Portfolio Management, Spring 1995, pp. 10 - 18.

Easley, David, and Maureen O'Hara. "Price, trade size, and information in securities markets.” Journal of Financial Economics, 19, 1987, pp. 69-90.

Easley, David, and Maureen O'Hara. "Order form and information in securities markets.” Journal of Finance 46, 1991, pp. 905-928.

Easley, David, and Maureen O'Hara. "Time and the process of security price adjustment." Journal of Finance, 47, 1992, 577-606.

Foucault, Thierry. "Order Flow Composition and Trading Costs in A Dynamic Order Driven Market.” Journal of Financial Markets, 2, 1999, pp. 99-134. 
Foucault, Thierry, Ohad Kaden and Eugene Kandel. "The Limit Order Book as a Market for Liquidity.” Review of Financial Studies, 18, 2005, pp. 1171-1217.

Francioni, Reto, Sonali Hazarika, Martin Reck and Robert A. Schwartz, "Security Market Microstructure: The Analysis of a Non-Frictionless Market," in Handbook of Quantitative Finance, Cheng-Few Lee and Alice C. Lee, eds., Springer, 2008, forthcoming.

Garman, Mark. "Market Microstructure." Journal of Financial Economics, June 1976, pp. 33-53.

Glosten, Lawrence, and Paul Milgrom. "Bid, ask, and transaction prices in a specialist market with heterogeneously informed agents.” Journal of Financial Economics, 14, 1985, pp. 71-100.

Glosten, Lawrence. “Is the Electronic Open Limit Order Book Inevitable?” Journal of Finance, 49, 1994, pp. 1127-1161.

Goettler, Ronald, Christine Parlour, and Uday Rajan. "Equilibrium in a Dynamic Limit Order Market.” Journal of Finance, 60, 2005, pp. 2149-2192.

Grossman, Sandford, 1992. "The information role of upstairs and downstairs markets.” Journal of Business, 65, pp. 509-529.

Grossman, Sandford, and Joseph Stiglitz. On the Impossibility of Informationally Efficient Markets. American Economic Review, 70, 3, 1980, pp. 393-408.

Handa, Puneet, and Robert Schwartz. "Limit Order Trading." Journal of Finance, December 1996a, pp. 1835 - 1861.

Handa, Puneet and Robert Schwartz, "How Best to Supply Liquidity to a Securities Market," Journal of Portfolio Management, Winter 1996b, pp. 44 - 51.

Handa, Puneet, Robert Schwartz, and Ashish Tiwari. "Quote Setting and Price Formation in an Order Driven Market.” Journal of Financial Markets, 2003, 6, pp 461-489.

Harris, Larry. Trading and Exchanges: Market Microstructure for Practitioners. 2003, Oxford University Press.

Harris, Larry. “Stock Price Clustering and Discreteness.” Review of Financial Studies, 4, 1991, pp. 389-415.

Harris, Larry. "Minimum Price Variations, Discrete Bid-Ask Spreads, and Quotation Sizes.” Review of Financial Studies, 7, 1994, pp. 149-178.

Hasbrouck, Joel. Empirical Market Microstructure. Oxford University Press, 2007. 
Hasbrouck, Joel. "Measuring the Information Content of Stock Trades.” Journal of Finance, 46, 1991, pp. 179-207.

Hasbrouck, Joel. "One security, many markets: Determining the contribution to price discovery.” Journal of Finance, 50, 1995, pp. 1175-1199.

Hasbrouck, Joel and Duane Seppi. "Common Factors in prices, order flows and liquidity.” Journal of Financial Economics, 59, 2001, pp. 383-411.

Hasbrouck, Joel, and George Sofianos. "The Trades of Market Makers: An Empirical Analysis of NYSE Specialists.” Journal of Finance, 48, 1993, pp. 1565-1593.

Ho, Thomas, and Hans Stoll. “On Dealer Markets under Competition.” Journal of Finance, 35, 1980, pp. 259-267.

Ho, Thomas, and Hans Stoll. "Optimal dealer pricing under transactions and return uncertainty.” Journal of Financial Economics, 9, 1981, pp. 47-73.

Ho, Thomas, and Hans Stoll. "The Dynamics of Dealer Markets under Competition.” Journal of Finance, 38, 1983, pp. 1053-1074.

Keim, Donald, and Ananth Madhavan. "The Upstairs Market for Large-Block Transactions: Analysis and Measurement of Price Effects." Review of Financial Studies, 9, 1996, pp. 1-36.

Kyle, Albert. “Continuous auctions and insider trading.” Econometrica, 53, 1985, pp. 1315-1335.

Madhavan, Ananth. Market Microstructure. Journal of Financial Markets, 2000, 3, pp. 205-258.

Madhavan, Ananth, and Minder Cheng. "In Search of Liquidity: An Analysis of Upstairs and Downstairs Trades.” Review of Financial Studies, 10, 1997, pp. 175-204.

Mendelson, Morris, Junius Peake and T. Williams, "Toward a Modern Exchange: The Peake-Mendelson-Williams Proposal for an Electronically Assisted Auction Market," in E. Bloch and R. Schwartz, eds. Impending Changes for Securities Markets: What Role for the Exchange? JAI Press, 1979.

Mildenstein, Eckart, and Harold Schleef. "The Optimal Pricing Policy of a Monopolistic Marketmaker in the Equity Market.” Journal of Finance, 38, 1983, pp. 218 -231.

Milgrom, Paul and Nancy Stokey. "Information, Trade and Common Knowledge." Journal of Economic Theory, 26, 1, 1982, pp. 17-27. 
Miller, Edward, “Risk, Uncertainty and Divergence of Opinion,” Journal of Finance, 1977, 32, 1151-1168.

O'Hara, Maureen. Market microstructure theory. Basil Blackwell, 1997, Cambridge, MA.

Ozenbas, Deniz, Robert Schwartz, and Robert Wood, "Volatility in U.S. and European Equity Markets: An Assessment of Market Quality,” International Finance, Volume 5 Number 3, Winter 2002, pp. 437-461.

Paroush, Jacob, Robert Schwartz, and Avner Wolf. "An Equity Market Where Fundamental Values Are Endogenous.” Working paper, City University of New York, 2007.

Parlour, Christine. "Price dynamics in limit order markets." Review of Financial Studies, 11, 1998, pp. 789-816.

Parlour, Christine and Duane Seppi. "Limit Order Markets: A Survey.” Forthcoming in Handbook of Financial Intermediation \& Banking edited by A.W.A. Boot and A. V. Thakor, 2008.

Pástor Luboš and Robert Stambaugh. "Liquidity risk and expected stock returns." Journal of Political Economy, 113, 2003, 642-685.

Sandas, Patrick, "Adverse Selection and Competitive Market Making: Empirical Evidence from a Limit Order Market.” Review of Financial Studies, 14, 2001, pp. 705734.

Seppi, Duane. "Equilibrium Block Trading and Asymmetric Information.” Journal of Finance, 45, 1990, pp. 73-94.

Stigler, George. "Public Regulation of the Securities Markets.” Journal of Business, April 1964, pp. 117-142.

Stoll, Hans. "The Supply of Dealer Services in Securities Markets.” Journal of Finance, 33, 1978, pp. 1133-1151.

Tinic, Sneha. “The Economics of Liquidity Services.” The Quarterly Journal of Economics, 86, 1, 1972, pp. 79-93.

Tinic, Sneha, and Richard West. "The Securities Industry under Negotiated Brokerage Commissions: Changes in the Structure and Performance of New York Stock Exchange Member Firms" Bell Journal of Economics, 11, (Spring 1980), pp. 29-41. 